\title{
Long-term outcome of ruptured abdominal aortic aneurysm: impact of treatment and age
}

\author{
This article was published in the following Dove Press journal: \\ Clinical Interventions in Aging \\ 13 October 2014 \\ Number of times this article has been viewed
}

\author{
Jelle W Raats' \\ Hans C Flu' \\ Gwan $\mathrm{H} \mathrm{Ho}$ \\ Eelco J Veen' \\ Louwerens D Vos ${ }^{2}$ \\ Ewout W Steyerberg ${ }^{3}$ \\ Lijckle van der Laan'
}

'Department of Surgery, Amphia Hospital, Breda, ${ }^{2}$ Department of Radiology, Amphia Hospital, Breda, ${ }^{3}$ Department of Public Health, Erasmus MC, Rotterdam, the Netherlands
Correspondence: Jelle W Raats Department of Surgery, Amphia Hospital, PO Box 90518, 4800 RK Breda, the Netherlands

Email jraats@amphia.nl
Background: Despite advances in operative repair, ruptured abdominal aortic aneurysm (rAAA) remains associated with high mortality and morbidity rates, especially in elderly patients. The purpose of this study was to evaluate the outcomes of emergency endovascular aneurysm repair (eEVAR), conventional open repair (OPEN), and conservative treatment in elderly patients with rAAA.

Methods: We conducted a retrospective study of all rAAA patients treated with OPEN or eEVAR between January 2005 and December 2011 in the vascular surgery department at Amphia Hospital, the Netherlands. The outcome in patients treated for rAAA by eEVAR or OPEN repair was investigated. Special attention was paid to patients who were admitted and did not receive operative intervention due to serious comorbidity, extremely advanced age, or poor physical condition. We calculated the 30-day rAAA-related mortality for all rAAA patients admitted to our hospital.

Results: Twelve patients did not receive operative emergency repair due to extreme fragility (mean age 87 years, median time to mortality 27 hours). Twenty-three patients had eEVAR and 82 had OPEN surgery. The 30-day mortality rate in operated patients was 30\% (7/23) in the eEVAR group versus $26 \%(21 / 82)$ in the OPEN group $(P=0.64)$. No difference in mortality was noted between eEVAR and OPEN over 5 years of follow-up. There were more cardiac adverse events in the OPEN group $(n=25,31 \%)$ than in the eEVAR group $(n=2,9 \% ; P=0.035)$. Reintervention after discharge was more frequent in patients who received eEVAR $(35 \%)$ than in patients who had OPEN $(6 \%, P<0.001)$. Advancing age was associated with increasing mortality (hazard ratio 1.05 [95\% confidence interval 1.01-1.09]) per year for patients who received operative repair, with a $67 \%, 76 \%$, and $100 \% 5$-year mortality rate in the 34 patients aged $<70$ years, 59 patients aged 70-79 years, and 12 octogenarians, respectively; 30-day rAAA-related mortality was also associated with increasing age $(21 \%, 30 \%$, and $61 \%$, respectively; $P=0.008)$.

Conclusion: The 30-day and 5-year mortality in patients who survived rAAA was equal between the treatment options of eEVAR and OPEN. Particularly fragile and very elderly patients did not receive operative repair. The decision to intervene in $\mathrm{rAAA}$ should not be made on the basis of patient age alone, but also in relation to comorbidity and patient preference.

Keywords: ruptured abdominal aneurysm repair, clinical decision-making, emergency endovascular aneurysm repair, open repair

\section{Introduction}

Rupture of an abdominal aortic aneurysm (AAA) is a catastrophic event, and is occurring with increasing frequency in our increasingly elderly population. ${ }^{1}$ The demographic trend toward an aging population in the Western world and an increasing incidence and prevalence of cardiovascular disease in the elderly are important considerations for health care professionals. Although the established definition of "elderly patients" in the current literature refers to people aged over 65 years, current demographic trends, improved 
health care, and understanding of the discrimination between biological age and chronological age dictates that the definition of an "elderly patient" may need to be revised. From a historical point of view, the conventional method used to repair a ruptured abdominal aortic aneurysm (rAAA) is open repair (OPEN) with replacement of the ruptured aneurysm using a synthetic tube graft. This extensive repair technique has a high mortality and morbidity rate in patients who are already reaching the limit of their physical reserves. ${ }^{2}$

Emergency endovascular aneurysm repair (eEVAR) is an alternative in patients with AAA and is becoming generally accepted in patients selected for planned AAA repair. The EVAR II trial reported no benefit for EVAR compared with no intervention in patients judged unfit for open elective AAA repair. ${ }^{3}$ However, several studies note that eEVAR could potentially reduce the morbidity and mortality rate. ${ }^{4-9}$ The minimally invasive nature of this technique allows aneurysm repair in patients with a rAAA who would be at significant risk in open surgery. Use of eEVAR could therefore be a viable alternative in patients suffering a rAAA, especially in the elderly. The current literature contains limited data on patients with a rAAA who arrive at hospital alive and do not receive emergency surgical repair. In our opinion, these data are of great importance in determining the outcome for elderly patients with rAAA who do and do not undergo emergency surgical repair. In this study, we analyzed our recent results for OPEN and eEVAR in rAAA patients, and describe patients who did not receive operative repair. We also investigated our results for $\mathrm{rAAA}$ repair in this elderly population according to age group.

\section{Patients and methods}

\section{Study design}

This study was evaluated and approved by the institutional review board at our hospital. A retrospective observational clinical review was conducted using data on 157 consecutive rAAA patients treated with OPEN or eEVAR between January 2005 and December 2011 in the vascular surgery department at Amphia Hospital, the Netherlands. Exclusion criteria were symptomatic AAA, acute onset of aortoduodenal fistula, and ruptured iliac aneurysm. Three patients who died prior to arrival in the operating theater were also excluded. Twelve patients did not receive operative emergency repair and were treated conservatively.

\section{Data analyzed per age group}

All data collected for the included patients were analyzed according to age group: $<70$ years (group $\mathrm{A}, \mathrm{n}=34,32 \%$ ),
70-79 years (group B, $\mathrm{n}=59,56 \%$ ), and $\geq 80$ years (group C, $\mathrm{n}=12,11 \%$ ). Operation-related 30-day mortality was defined as mortality in the first 30 days after surgical repair (eEVAR or OPEN); rAAA-related mortality was defined as mortality for all rAAA patients in the first 30 days after admission to our hospital regardless of whether or not they underwent operative repair $(n=117)$.

\section{Risk factors and comorbidity}

Risk factors, comorbidity, vital signs, and biochemistry tests were performed prospectively in all patients during their admission. Management of risk factors and comorbidity, according to the Trans-Atlantic Inter-Society Consensus Document on Management of Peripheral Arterial Disease ${ }^{10}$ and the American Heart Association/American College of Cardiology, ${ }^{11}$ was undertaken by a vascular specialist or cardiologist preoperatively whenever possible. Data on patient characteristics, risk factors, and comorbidity are listed in Table 1. An overview of rAAA patients with conservative management are shown in Table 2.

\section{rAAA characteristics}

The definition of rAAA used was hemorrhage outside the aortic wall and diagnosis by multislice computed tomography (CT) (Siemens Definition scanner, Siemens, Munich, Germany). Some patients were hemodynamically unstable and no imaging could be performed, so the diagnosis was confirmed intraoperatively. Data on rAAA characteristics are shown in Table 1.

\section{Revascularization}

All vascular and endovascular procedures were performed by certified vascular surgeons and interventional radiologists who were available around the clock.

\section{eEVAR}

Two stent graft systems were used for treatment of rAAAs during the study periods: the Cook $^{\circledR}$ Zenith Flex ${ }^{\circledR}$ aortouni-iliac (AUI) device stent graft system (Cook Medical, Bloomington, IL, USA) $)^{12}$ in 2005-2008 and the Medtronic ${ }^{\circledR}$ Endurant ${ }^{\circledR}$ II AUI device (Medtronic Inc, Minneapolis, MN, USA) and aorto-bi-iliac stent graft system in 2008-2011. ${ }^{13}$ All AUI endografting was combined with femorofemoral crossover bypass and deployment of an occluder cuff in the contralateral common iliac artery. The requirements for these standard available stent grafts were driven by the Society of Vascular Surgery/North American Chapter of the International Society for Cardiovascular surgery (SVERSUS/ISCVERSUS) ${ }^{14}$ 
Table I Characteristics of all patients treated for a rAAA by OPEN or eEVAR in 2005-20I I

\begin{tabular}{|c|c|c|c|c|}
\hline Characteristics & Total $n=105$ & OPEN $n=82$ & eEVAR $\mathrm{n}=\mathbf{2 3}$ & $P$-value \\
\hline \multicolumn{5}{|l|}{ Sex } \\
\hline Male & $86(82)$ & $69(84)$ & $17(74)$ & 0.260 \\
\hline Female & $19(18)$ & $13(16)$ & $6(26)$ & 0.260 \\
\hline \multicolumn{5}{|l|}{ Age } \\
\hline Median age, years (range) & $73(54-89)$ & 7I (54-87) & 77 (64-89) & $<0.00 I^{*}$ \\
\hline$<70$ & $34(32)$ & $33(40)$ & I (4) & $0.001 *$ \\
\hline 70-79 & $59(56)$ & $40(49)$ & $19(83)$ & $0.004 *$ \\
\hline$\geq 80$ & $12(11)$ & $9(\mathrm{II})$ & $3(13)$ & 0.783 \\
\hline HD-stable & $48(46)$ & $37(54)$ & II (48) & 0.818 \\
\hline $\mathrm{SBP}>80 \mathrm{mmHg}$ & $61(58)$ & $45(55)$ & $16(70)$ & 0.207 \\
\hline \multicolumn{5}{|l|}{ CT scan obtained } \\
\hline Yes & $80(76)$ & $57(70)$ & $23(100)$ & $0.002 *$ \\
\hline No & $25(24)$ & $25(3 I)$ & $0(0)$ & $0.002 *$ \\
\hline \multicolumn{5}{|l|}{ Diameter AAA } \\
\hline Median aneurysm, mm (range) & $80.0(4.5-13.8)$ & $80.0(4.5-13.8)$ & $70.0(5.0-10.0)$ & $0.044^{*}$ \\
\hline \multicolumn{5}{|l|}{ Comorbidity and risk factors } \\
\hline Cardiac disease & $47(45)$ & $37(45)$ & $10(44)$ & 0.889 \\
\hline Pulmonary disease & $29(28)$ & $22(27)$ & $7(30)$ & 0.733 \\
\hline Renal disease & $10(10)$ & $8(10)$ & $2(9)$ & 0.878 \\
\hline Diabetes mellitus & $12(11)$ & $7(89)$ & $5(22)$ & 0.079 \\
\hline Hypertension & $51(49)$ & $38(46)$ & $13(57)$ & 0.388 \\
\hline Hyperlipidemia & $12(11)$ & $11(13)$ & I (4) & 0.227 \\
\hline Peripheral arterial occlusive disease & $8(8)$ & $6(7)$ & $2(9)$ & 0.826 \\
\hline Tobacco use & $44(42)$ & $37(45)$ & $7(30)$ & 0.429 \\
\hline \multicolumn{5}{|l|}{ Secondary prevention } \\
\hline Antiplatelet agent & $42(40)$ & $31(38)$ & II (48) & 0.386 \\
\hline Statin & $35(33)$ & $27(33)$ & $8(35)$ & 0.867 \\
\hline Coumarins & $13(12)$ & $12(15)$ & I (4) & 0.180 \\
\hline
\end{tabular}

Note: Data are presented as the $\mathrm{n}(\%)$, unless otherwise specified. $*$ p-value $<0.05$.

Abbreviations: AAA, abdominal aortic aneurysm; eEVAR, emergency endovascular aneurysm repair; OPEN, open repair; HD-stable, hemodynamically stable; SBP, systolic blood pressure in $\mathrm{mmHg}$; $\mathrm{CT}$, computed tomography.

and the European Society for Vascular Surgery reporting standards. ${ }^{15}$ The eEVAR procedure was performed according to standard vascular and endovascular techniques.

It was recommended that eEVAR be performed under local anesthesia in the groin at the selected access site. After the AUI was inserted and antegrade flow into the rAAA sac was blocked, general anesthesia could be given to perform the subsequent operative steps, ie, deployment of the common iliac occluder cuff and completion of the femorofemoral crossover bypass. All patients met the criteria as listed in the instructions for use, according to component placement and sizing guidelines.

\section{OPEN}

The OPEN procedure was performed according to standard vascular and endovascular techniques following the SVERSUS/ISCVERSUS guidelines..$^{14}$ An anterior transperitoneal approach was used in all patients; after aortic clamping, a minimal dissection, and when necessary, intrasaccular ligation of the lumbar artery branches, was performed. Subsequently, suture attachment of the prosthetic graft to the proximal and distal aspects of the aneurysm was undertaken. Aortoaortic "straight tube" grafts and bifurcated prostheses were used. The operative data for patients who underwent OPEN or eEVAR are listed in Table 3.

\section{Admission and follow-up General}

Preoperative and operative data were collected. During follow-up, data on mortality, hospital (surgical ward) stay, and intensive care unit (ICU) stay were registered. Mortality data were retrieved using the national death registry.

\section{Adverse events}

In the Netherlands, the Association of Surgeons of the Netherlands has agreed on one common definition of adverse events (AEs). ${ }^{16-20}$ This definition differs from that used in other studies because it has been chosen with the explicit 
Table 2 Patient overview for rAAA with conservative management $(n=12)$

\begin{tabular}{|c|c|c|c|c|c|}
\hline Case & HD-stable & Age (years) & Rationale for conservative management & Time to mortality & $\begin{array}{l}\text { Time to mortality } \\
\text { in hours }\end{array}$ \\
\hline 1 & Yes & 87 & $\begin{array}{l}\text { Medical history included AAA; decision for } \\
\text { conservative treatment was made prior to } \\
\text { rupture. }\end{array}$ & $<48$ hours & 27 \\
\hline 2 & Yes & 89 & $\begin{array}{l}\text { Diagnosis was confirmed with uncontrasted } \\
\text { CT scan. Died I } 5 \text { months later due to repeat } \\
\text { rAAA. Complex morphology aneurysm. } \\
\text { Conservative due to high age and } \\
\text { comorbidity. }\end{array}$ & 483 days ( 15 months) & Unknown \\
\hline 3 & Unknown & 91 & On demand of patient and family. & $<48$ hours & 33 \\
\hline 4 & No & 92 & $\begin{array}{l}\text { Complex morphology aneurysm, not eEVAR } \\
\text { suitable. }\end{array}$ & $<24$ hours & Unknown \\
\hline 5 & No & 87 & $\begin{array}{l}\text { Conservative management due to high age } \\
\text { and comorbidity. }\end{array}$ & $<24$ hours & 4 \\
\hline 6 & No & 83 & Arrived undergoing CPR. Poor prognosis. & $<24$ hours & 2 \\
\hline 7 & Yes & 85 & $\begin{array}{l}\text { Complex morphology aneurysm, not eEVAR } \\
\text { suitable. On demand of patient and family, no } \\
\text { open repair. }\end{array}$ & $<48$ hours & 32 \\
\hline 8 & No & 89 & $\begin{array}{l}\text { Conservative due to high age and comorbidity } \\
\text { including severe dementia. }\end{array}$ & $<48$ hours & 26 \\
\hline 9 & No & 77 & $\begin{array}{l}\text { On demand of patient. History included } \\
\text { end-stage prostate carcinoma. }\end{array}$ & $<48$ hours & 37 \\
\hline 10 & No & 90 & Due to high age. & $<48$ hours & 31 \\
\hline II & Yes & 82 & $\begin{array}{l}\text { Complex morphology aneurysm, not eEVAR } \\
\text { suitable. On demand of patient and family, no } \\
\text { open repair due to high age and comorbidity. }\end{array}$ & $<24$ hours & 12 \\
\hline 12 & Yes & 93 & $\begin{array}{l}\text { Due to high age and comorbidity, including } \\
\text { severe cardiac failure. }\end{array}$ & $<24$ hours & 2 \\
\hline
\end{tabular}

Abbreviations: AAA, abdominal aortic aneurysm; rAAA, ruptured abdominal aortic aneurysm; eEVAR, emergency endovascular aneurysm repair; HD-stable, hemodynamically stable; CT, computed tomography; CPR, cardiopulmonary resuscitation.

aim of excluding subjective judgment on cause and effect, and right and wrong. The definition of an AE is:

An unintended and unwanted event or state occurring during or following medical care, that is so harmful to a patient's health that (adjustment of) treatment is required or that permanent damage results. The AE may be noted during hospitalization, until 30 days after discharge. ${ }^{20}$

Table 3 Summary of OPEN $(n=82)$ and eEVAR procedures $(n=23)$ in all patients treated for a rAAA

\begin{tabular}{|c|c|}
\hline \multicolumn{2}{|l|}{ OPEN } \\
\hline Tube graft & $58(7 \mid)$ \\
\hline Bi-iliac tube graft & $19(23)$ \\
\hline Died prior to placement of graft & $5(6)$ \\
\hline \multicolumn{2}{|l|}{ eEVAR } \\
\hline \multicolumn{2}{|c|}{ Cook $^{\circledR}$ Zenith Flex ${ }^{\circledR}$ AAA (AUI) endovascular } \\
\hline Graft system & $12(52)$ \\
\hline \multicolumn{2}{|c|}{ Medtronic ${ }^{\circledR}$ Endurant ${ }^{\circledR}$ AAA stent graft system } \\
\hline AUl stent graft system & $5(22)$ \\
\hline$A B \mid$ stent graft system & $6(26)$ \\
\hline
\end{tabular}

Note: Data are presented as $n(\%)$.

Abbreviations: rAAA, ruptured abdominal aortic aneurysm; OPEN, open repair; eEVAR, emergency endovascular aneurysm repair; $A U I$, aorto-uni-iliac; $A B I$, aorto-bi-iliac.

\section{Endoleaks}

The definition of endoleak, the decision to intervene, and the type of reintervention, ie, endovascular or surgical, were driven by the SVERSUS/ISCVERSUS ${ }^{14}$ and European Society for Vascular Surgery reporting standards and were registered. ${ }^{15}$

\section{Statistical analysis}

The statistical analysis was performed using Statistical Package for the Social Sciences version 20 software (IBM Corporation, Armonk, NY, USA). Following completion of the data collection, univariate analyses were performed using the chi-square and unpaired Student's $t$-tests. Survival was estimated by logistic regression analysis (30-day mortality) and Cox regression analysis (long-term mortality, with patients included to date of last follow-up or death).

\section{Results}

\section{Patient selection process}

Between January 2005 and December 2011, 157 patients were admitted to our hospital with a diagnosis of rAAA or 
symptomatic AAA (Figure 1). Thirty-seven patients were excluded due to diagnosis of a symptomatic non-ruptured AAA. Twelve patients (mean age $87 \pm 4.6$ years) did not undergo surgical intervention and were treated conservatively for several different reasons, as listed in Table 2. One patient died after 15 months, and in this case a diagnosis of rAAA was confirmed by uncontrasted CT due to significant renal impairment. The remaining eleven patients died within 48 hours (median mortality at 27 hours). Three patients died in the emergency room and were excluded. Of the 105 patients included, 82 (78\%) underwent OPEN and 23 (22\%) received eEVAR.

\section{Patient characteristics and comorbidity}

Patients in the eEVAR group were significantly older (median age 77 years) than those in the OPEN group (median age 71 years; $P<0.001)$. There were more men ( $n=69,84 \%)$ in the OPEN group than in the eEVAR group $(n=17,74 \%$; $P=0.26$ ). No difference in hemodynamic status at admission

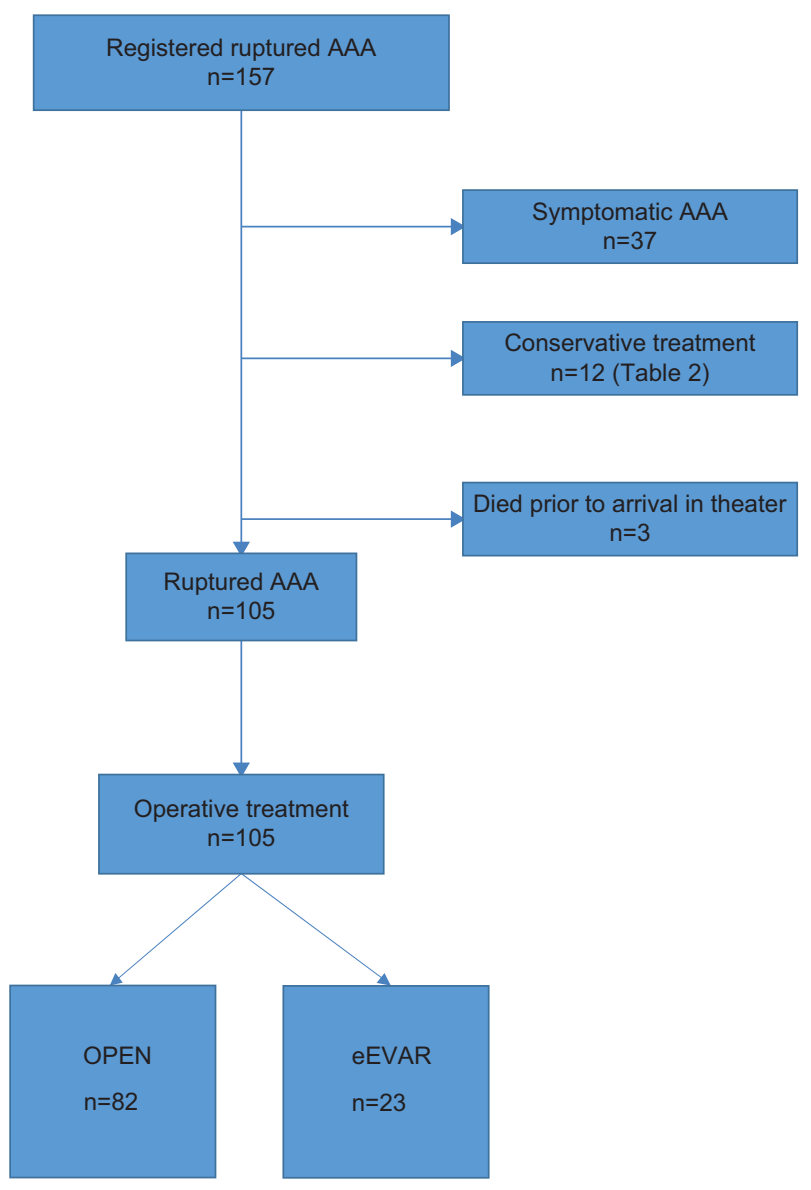

Figure I Patient flow through identification and selection process. Abbreviations: AAA, abdominal aortic aneurysm; eEVAR, emergency endovascular aneurysm repair; OPEN, conservative open repair. was detected between both groups. Comorbidity and risk factors were similar in both groups (Table 1).

\section{Characteristics of rAAA}

A CT scan was done in all 23 eEVAR patients and in 57 OPEN patients $(70 \% ; P=0.002)$. The median rAAA diameter in patients treated by eEVAR $(70 \mathrm{~mm})$ was significantly larger than in patients treated by OPEN $(80 \mathrm{~mm} ; P=0.044)$.

\section{Revascularization}

In one patient, eEVAR was converted to an OPEN procedure due to persistent hemodynamic instability and development of a distended abdomen during surgery (Table 3 ). This patient died directly after completion of a celiotomy, most likely due to exsanguination. In another patient, eEVAR was converted to OPEN with placement of a tube graft due to technical problems during placement of the main device.

\section{eEVAR-related reinterventions and endoleaks}

We documented three type I, four type IIa, four type IIb, and two type III endoleaks, as shown in Table 4. No type IV or type $\mathrm{V}$ endoleaks were noted. Overstenting of four renal arteries occurred in three patients receiving eEVAR. Two patients underwent a Hartmann procedure because of bowel ischemia. Another two patients were reoperated because of an infected prosthesis (one with an infected EVAR and one with an infected femorofemoral crossover bypass). Other surgical adverse events and reinterventions are listed in Table 4.

\section{Adverse events and reinterventions}

At least one AE occurred in the eEVAR and OPEN patients, $(n=14[61 \%]$ versus $n=53[65 \%])$ respectively. There were more cardiac AEs in the OPEN group $(n=25,31 \%)$ than in the eEVAR group $(\mathrm{n}=2,9 \% ; P=0.035)$. Cerebrovascular accidents occurred only in the eEVAR group $(n=2,9 \% ; P=0.007)$, as shown in Table 5. There were more reinterventions during follow-up in the rAAA patients who underwent eEVAR $(\mathrm{n}=8,35 \%)$ than in those who underwent OPEN ( $\mathrm{n}=5,6 \%$; $P<0.001)$, as indicated in Table 6 .

\section{Length of stay}

Hospital stay was not significantly longer in the OPEN group (mean 17 days) when compared with the eEVAR group (mean 12 days). Patients in both groups were admitted to the ICU for a mean of 7 days postoperatively. The data are summarized in Table 7. 
Table 4 Summary of endoleaks and adverse events after all eEVAR procedures $(n=23)$ in patients treated for a rAAA

\begin{tabular}{l}
$\begin{array}{l}\text { Endoleak } \\
\text { or surgical } \\
\text { complication }\end{array}$ \\
\hline
\end{tabular}

Endoleak type I

$3^{\mathrm{a}}$

${ }^{a}$ One died, one successfully treated by PTA, one treated by main device in main

\section{Endoleak type 2a 2}

Endoleak type $2 b$

Endoleak type 3

Ischemic colitis

Overstenting

$3^{g}$

of renal artery

Infected

$I^{\text {h }}$

prosthesis

fistula

Died on table

after correct

placement

Anastomotic

aneurysm of

femorofemoral

crossover bypass device placement.
I

2

$I^{c}$

$I^{b}$

I

$I^{\mathrm{e}}$
'Ligation of $2 \mathrm{~A}$.

'Ligation of IMA.

${ }^{d}$ Occluder plug insufficient, coiling of 2A unsuccessful, ligation of EIA and femorofemoral crossover.

eSurgical repair with interpositional graft.

fTwo Hartmann procedures, in one patient complicated by parastomal herniation 2 years after surgery.

gIn one patient with a juxtarenal aneurysm and no open surgical possibilities due to severe intra-abdominal adhesions, overstenting of both renal arteries.

hReoperation with replacement with an antibiotic drained prosthesis. infected femorofemoral crossover with replacement with an autologous crossover bypass.

JConservative treatment, patient died.

$\mathrm{I}^{\mathrm{i}}$

Redone.

Note: All endoleaks and surgical complications were managed conservatively unless otherwise mentioned.

Abbreviations: eEVAR, emergency endovascular aneurysm repair; rAAA, ruptured abdominal aortic aneurysm; PTA, percutaneous transluminal angioplasty; 2A, internal iliac artery (hypogastric artery); IMA, inferior mesenteric artery; EIA, external iliac artery. 
Table 5 Adverse events in all patients treated for a rAAA with eEVAR or OPEN in 2005-20II

\begin{tabular}{|c|c|c|c|c|}
\hline Description of adverse event & Total $n=105$ & OPEN $n=82$ & eEVAR $\mathrm{n}=\mathbf{2 3}$ & $P$-value \\
\hline Any adverse event & $67(64)$ & $53(65)$ & $14(61)$ & 0.740 \\
\hline Any cardiac $\mathrm{AE}$ & $27(26)$ & $25(31)$ & $2(9)$ & $0.035^{*}$ \\
\hline Myocardial infarction & $4(4)$ & $4(5)$ & $0(0)$ & 0.280 \\
\hline Cardiac arrest & $5(5)$ & $4(5)$ & I (4) & 0.916 \\
\hline Heart failure & $14(13)$ & $12(15)$ & $2(9)$ & 0.459 \\
\hline Brady/tachycardia & $3(3)$ & $2(2)$ & I (4) & 0.627 \\
\hline Atrial fibrillation & $7(7)$ & $6(7)$ & I (4) & 0.614 \\
\hline Any pulmonary AE & $36(34)$ & $29(35)$ & $7(30)$ & 0.660 \\
\hline Respiratory insufficiency & $16(15)$ & $11(13)$ & $5(22)$ & 0.326 \\
\hline Pneumonia & $37(35)$ & $31(38)$ & $6(26)$ & 0.299 \\
\hline Pleural fluid & $5(5)$ & $5(6)$ & $0(0)$ & 0.225 \\
\hline Atelectasis & $2(2)$ & $2(2)$ & $0(0)$ & 0.450 \\
\hline Any neurologic $A E$ & $4(4)$ & $2(2)$ & $2(9)$ & 0.316 \\
\hline Cerebrovascular accident & $2(2)$ & $0(0)$ & $2(9)$ & $0.007^{*}$ \\
\hline Neuropraxia & $2(2)$ & $2(2)$ & $0(0)$ & 0.450 \\
\hline Any renal $\mathrm{AE}$ & $30(29)$ & $26(32)$ & $4(7)$ & 0.179 \\
\hline Renal failure & $25(24)$ & $20(24)$ & $5(22)$ & 0.792 \\
\hline Renal failure hemodialysis & $15(14)$ & $12(15)$ & $3(13)$ & 0.847 \\
\hline Urinary tract infection & $4(4)$ & $4(5)$ & $0(0)$ & 0.280 \\
\hline Urinary retention & $2(2)$ & $2(2)$ & $0(0)$ & 0.450 \\
\hline Wound infection & $4(4)$ & $3(4)$ & I (4) & 0.879 \\
\hline Wound dehiscence & $\mathrm{I}(\mathrm{I})$ & $I(I)$ & $0(0)$ & 0.595 \\
\hline Compartment syndrome & $2(2)$ & $2(2)$ & $0(0)$ & 0.450 \\
\hline Fascia dehiscence & $2(2)$ & $2(2)$ & $0(0)$ & 0.450 \\
\hline Bowel ischemia & $10(10)$ & $7(9)$ & $3(13)$ & 0.515 \\
\hline Bowel ischemia requiring resection & $6(6)$ & $4(5)$ & $2(9)$ & 0.452 \\
\hline Infected tube graft & $2(2)$ & $\mathrm{I}(\mathrm{I})$ & I (4) & 0.332 \\
\hline
\end{tabular}

Notes: Data are presented as $n(\%)$. $* P$-value $<0.05$.

Abbreviations: AE, adverse event; rAAA, ruptured abdominal aortic aneurysm; eEVAR, emergency endovascular aneurysm repair; OPEN, open repair.

\section{Mortality}

The 30-day mortality rate was 30\% (7/23) in eEVAR patients versus $26 \%(21 / 82)$ in OPEN patients $(P=0.64)$. Intraoperative mortality was comparable in both groups; two patients $(9 \%)$ died during eEVAR and nine patients during OPEN $(11 \% ; P=0.752)$. No difference in mortality in 1-year, 3 -year, and 5-year follow-up was found between eEVAR and OPEN. The data are summarized in Table 7.

\section{Impact of age}

There were fewer male patients $(67 \%)$ in group C (age $\geq 80$ years $)$ than in group $\mathrm{A}(97 \%$, age $<70$ years $)$ and group B ( $76 \%$, age $70-79$ years; $P=0.015)$. There were no significant differences in operation-related 30 -day mortality
$(21 \%, 29 \%$, and $33 \%)$ between groups A, B, and C, respectively, if patients underwent surgery (Table 8). Increasing age was associated with mortality during 5-year follow-up ( $P=0.012$, hazard ratio 1.049 [1.01-1.09]). The rAAA-related mortality increased with advancing age $(21 \%, 30 \%$, and $61 \%$ for groups $\mathrm{A}, \mathrm{B}$, and $\mathrm{C}$, respectively; $P=0.008)$. At least one $\mathrm{AE}$ occurred in $75 \%$ of patients in group $\mathrm{C}$; however, there was no statistically significant difference when compared with the other age groups (Table 9). A survival curve per age group is shown in Figure 2.

\section{Discussion}

Clinicians are being increasingly faced with fragile elderly patients in a poor mental and physical state. This problem is

Table 6 Reintervention rates with details of rAAA patients receiving OPEN or eEVAR in 2005-20I I

\begin{tabular}{lll}
\hline Intervention & OPEN n=82 & eEVAR n=23 \\
\hline Patients with any reintervention & $26(32)$ & II (48) \\
Reintervention during 30-day postoperative period & $22(27)$ & $4(17)$ \\
Reintervention during follow-up & $5(6)$ & 0.153 \\
\hline
\end{tabular}

Note: Data are presented as the $\mathrm{n}(\%)$.

Abbreviations: rAAA, ruptured abdominal aortic aneurysm; OPEN, open repair; eEVAR, emergency endovascular aneurysm repair. 
Table 7 Mortality and hospital stay in all patients treated for a rAAA with eEVAR or OPEN in 2005-20II

\begin{tabular}{|c|c|c|c|c|}
\hline & Total $n=105$ & OPEN $n=82$ & eEVAR $n=23$ & $P$-value \\
\hline \multicolumn{5}{|l|}{ Mortality } \\
\hline Intraoperative mortality & $1 \mathrm{I} / 105(10)$ & $9 / 82(\mathrm{II})$ & $2 / 23(9)$ & 0.752 \\
\hline 30-day mortality rate & $28 / 105(27)$ & $21 / 82(26)$ & $7 / 23(30)$ & $0.644^{\mathrm{a}}$ \\
\hline I-year mortality rate & $38 / 105(36)$ & $30 / 82(37)$ & $8 / 23(35)$ & $0.913^{\mathrm{b}}$ \\
\hline 3-year mortality rate & $47 / 89(53)$ & $37 / 70(53)$ & $10 / 19(53)$ & $0.913^{\mathrm{b}}$ \\
\hline 5-year mortality rate & $57 / 75(76)$ & $44 / 58(76)$ & $13 / 17(76)$ & $0.913^{b}$ \\
\hline \multicolumn{5}{|l|}{ Duration of in-hospital stay } \\
\hline Mean (SD) length of hospital stay, days & $16(15)$ & $17(16)$ & $12(9)$ & 0.212 \\
\hline Mean (SD) length of ICU stay in days & $7(I I)$ & $7(I I)$ & $7(12)$ & 0.922 \\
\hline
\end{tabular}

Notes: Data are presented as the $\mathrm{n}(\%)$, unless otherwise specified; alogistic regression analysis; ${ }^{\circ}$ Cox regression analysis.

Abbreviations: rAAA, ruptured abdominal aortic aneurysm; OPEN, open repair; eEVAR, emergency endovascular aneurysm repair; ICU, intensive care unit; SD, standard deviation.

of major importance, with population projections indicating that the number of persons aged over 80 years will double during the next 30 years. ${ }^{21}$ rAAA is associated with high mortality and significant comorbidity, especially in the very elderly. ${ }^{2}$ Supportive medical care for critically ill patients has improved over recent decades, and as supportive technologies become more advanced, surgeons should reconsider the expediency of comprehensive potentially life-saving interventions and extensive surgery in the elderly population.

\section{Nonoperated patients}

Interest in EVAR techniques has increased in recent years, and more studies noting potentially improved mortality and morbidity outcomes have been published. Every clinician who deals with vascular emergencies has experienced the ethical dilemma of whether to offer a probably hopeless but potentially life-saving intervention when a very elderly comorbid patient presents with a rAAA. The decision for OPEN or eEVAR in a rAAA case must be made according to the wishes of the patient and family, ie, whether to proceed with emergency repair or provide comfort measures. The decision should be made with serious consideration and care, and could be challenging because of the time factor. Evidence to guide this clinical decision is scarce in current literature. It has been reported that $10 \%-26 \%$ of patients with a rAAA who reach hospital alive are treated conservatively because of their extensive comorbidity and advanced age. ${ }^{22,23}$

There was a high mean age of 87 years in patients who were treated conservatively, compared with other studies reporting that $75 \%$ of the rAAA patients treated conservatively were $>80$ years. ${ }^{24}$ In this study, advanced age in combination with frailty was mentioned most frequently as the reason for conservative treatment. As in the literature, ${ }^{24}$ the average time to death following rAAA without repair was 7 hours.

Table 8 Operation-related mortality for a rAAA after eEVAR or OPEN, and rAAA-related mortality per age group

\begin{tabular}{|c|c|c|c|c|c|c|}
\hline & $\begin{array}{l}\text { Total } \\
\text { All age groups }\end{array}$ & $\begin{array}{l}\text { Group A } \\
\text { Age }<\mathbf{7 0} \text { years }\end{array}$ & $\begin{array}{l}\text { Group B } \\
\text { Age } 70-79 \text { years }\end{array}$ & $\begin{array}{l}\text { Group } C \\
\text { Age } \geq 80 \text { years }\end{array}$ & $P$-value & HR (95\% Cl) \\
\hline $\begin{array}{l}\text { All rAAA patients treated } \\
\text { with eEVAR or OPEN }\end{array}$ & $n=105$ & $n=34$ & $n=59$ & $n=12$ & & \\
\hline $\begin{array}{l}\text { Operation-related 30-day } \\
\text { mortality rate }\end{array}$ & $28 / 105(27)$ & $7 / 34(21)$ & $17 / 59(29)$ & $4 / 12(33)$ & $0.059^{a}$ & $1.9(0.45-8.30)$ \\
\hline I-year mortality rate & $38 / 105(36)$ & I I/34 (23) & $22 / 59(37)$ & $5 / 12(42)$ & $0.012^{\mathrm{b}}$ & $1.049(1.01-1.09)$ \\
\hline 3-year mortality rate & $47 / 89(53)$ & I3/28 (46) & $27 / 51(53)$ & $7 / 10$ (70) & $0.012^{\mathrm{b}}$ & $1.049(1.01-1.09)$ \\
\hline 5-year mortality rate & $57 / 75(76)$ & $16 / 24(67)$ & $3 I / 4 \mid(76)$ & $10 / 10(100)$ & $0.012^{b}$ & $1.049(1.01-1.09)$ \\
\hline $\begin{array}{l}\text { All rAAA patients } \\
\text { (treated operatively or } \\
\text { nonoperatively) }\end{array}$ & $n=117$ & $n=34$ & $n=60$ & $n=23$ & & \\
\hline $\begin{array}{l}\text { rAAA-related 30-day } \\
\text { mortality rate }\end{array}$ & $39 / 117(33)$ & $7 / 34(21)$ & $18 / 60(30)$ & $\mid 4 / 23(6 \mid)$ & $0.008^{\mathrm{a}}$ & $6.0(1.84-19.53)$ \\
\hline
\end{tabular}

Notes: Data are presented as the $\mathrm{n}(\%)$. Group A, age $<70$ years; Group B, $70-79$ years; Group C, age $\geq 80$ years. ${ }^{\text {Logistic }}$ regression analysis. ${ }^{\mathrm{b}}$ Cox regression analysis. 'Addition of nonoperated patients with rAAA ( $n=117)$.

Abbreviations: rAAA, ruptured abdominal aortic aneurysm; OPEN, open repair; eEVAR, emergency endovascular aneurysm repair; HR, hazard ratio; Cl, confidence interval. 
Table 9 Data for patients treated for a rAAA with eEVAR or OPEN after inclusion according to age group

\begin{tabular}{|c|c|c|c|c|}
\hline & $\begin{array}{l}\text { Group A } \\
\text { Age }<70 \text { years } \\
n=34\end{array}$ & $\begin{array}{l}\text { Group B } \\
\text { Age } 70-79 \text { years } \\
n=59\end{array}$ & $\begin{array}{l}\text { Group C } \\
\text { Age } \geq 80 \text { years } \\
n=12\end{array}$ & $P$-value \\
\hline \multicolumn{5}{|l|}{ Adverse events } \\
\hline Any AE & $18(53)$ & $40(68)$ & $9(75)$ & NS \\
\hline Any cardiac $\mathrm{AE}$ & $7(2 I)$ & $15(25)$ & $5(42)$ & NS \\
\hline Any pulmonary $\mathrm{AE}$ & $10(2)$ & $21(36)$ & $5(42)$ & NS \\
\hline Any neurologic $A E$ & $0(0)$ & $2(3)$ & $2(17)$ & NS \\
\hline Any renal $\mathrm{AE}$ & $8(24)$ & $18(3 \mid)$ & $4(33)$ & NS \\
\hline \multicolumn{5}{|l|}{ Hospital stay } \\
\hline Mean (SD) length of ICU stay in days & $3.9(4)$ & $8.6(13)$ & $6.4(9)$ & NS \\
\hline Mean (SD) length of hospital stay in days & $12.3(7)$ & $17.8(17)$ & $15.3(20)$ & NS \\
\hline
\end{tabular}

Notes: Data are presented as the $n$ (\%), unless otherwise specified. Group A, age $<70$ years; Group B, 70-79 years; Group C, age $\geq 80$ years.

Abbreviations: AE, adverse event; $r A A A$, ruptured abdominal aortic aneurysm; OPEN, open repair; eEVAR, emergency endovascular aneurysm repair; ICU, intensive care unit; SD, standard deviation; NS, not statistically significant.

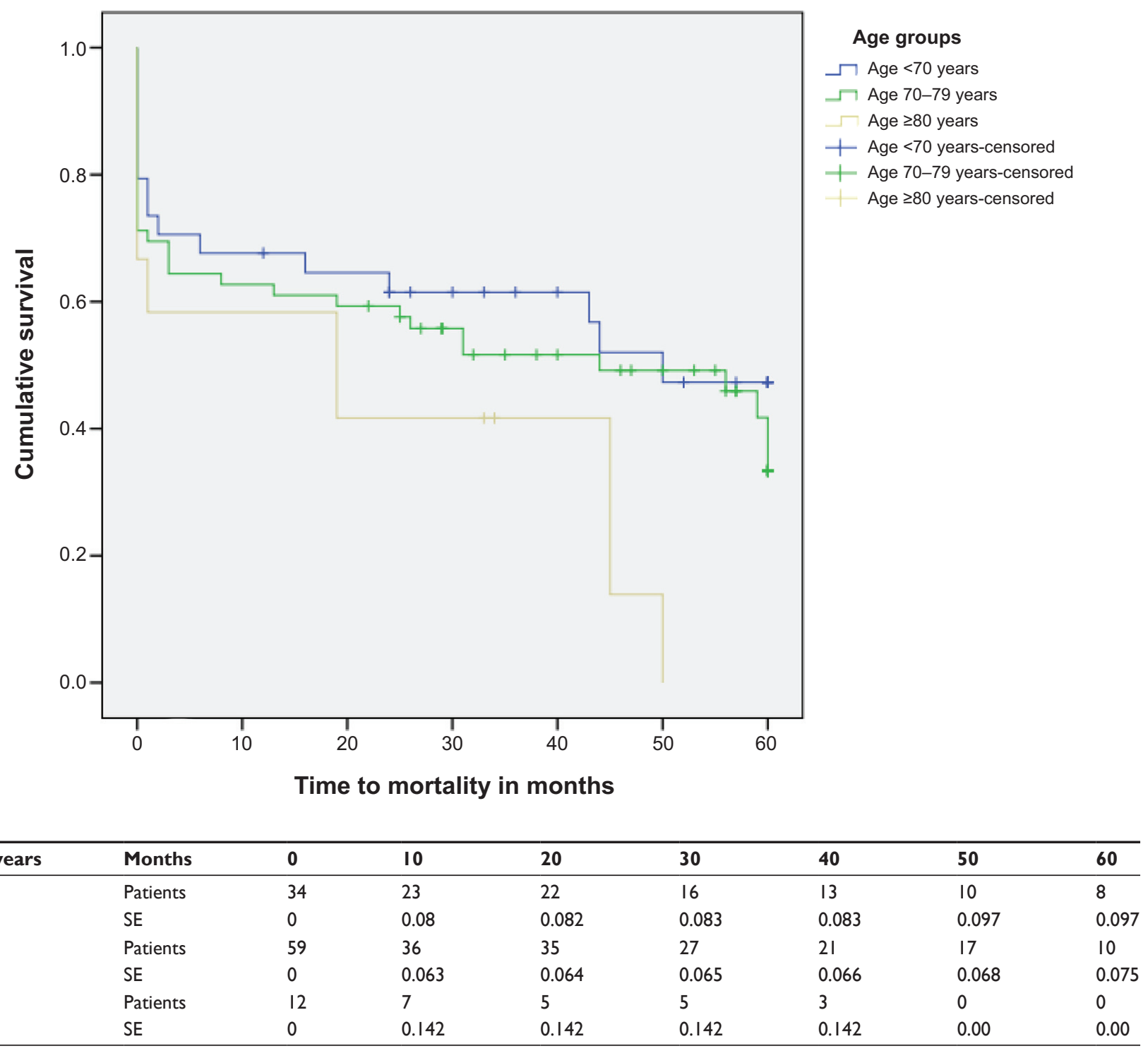

Figure 2 Survival per age group.

Notes: Kaplan-Meier curves representing survival per age group. Censored patients are patients where follow-up could not completed within 60 months because they were included at the end of the study period.

Abbreviation: SE, standard error. 


\section{Treatment: OPEN and eEVAR}

\section{Adverse events}

There were high AE rates in both treatment groups. In contrast with other studies, cardiac AEs were significantly more common in the OPEN group. ${ }^{25-29}$ These high rates could be explained partly by our broad definition and strict protocol for registration of AEs. Strokes occurred in the patients who received eEVAR, and this may be related to the guide wire in the aortic arch during the procedure. There was no significant difference in AEs per age group, and this could probably be explained by selection bias.

\section{Reinterventions}

The risk of a reintervention and readmission is higher after eEVAR than after OPEN, ${ }^{30}$ particularly in very elderly patients. Edwards et al reported significant higher endovascular reintervention rates in 3-year follow-up for patients with rAAA treated by eEVAR (10.9\%) when compared with patients treated by OPEN $(1.5 \%) .{ }^{31}$ Similarly, we report a reintervention rate of $35 \%$ for patients treated by eEVAR and $6 \%$ for those treated by OPEN over 5 years of follow-up. A possible explanation is the fact that endoleaks and reinterventions for possible endoleaks occur only after eEVAR and not after OPEN. In contrast with our study, the literature reports that rAAA patients treated with eEVAR resulting in postoperative reinterventions had significant 30 -day mortality. ${ }^{30}$

\section{Hospital and ICU stay}

In the current literature, there is significant heterogeneity with regard to reported hospital stay, ie, 9-15 days for eEVAR and 10-26 days for OPEN. ${ }^{29,32-35} \mathrm{We}$ found no difference in the recorded hospital and ICU stay between patients treated with eEVAR or OPEN. Other studies have reported ICU stays of 0-5 days in eEVAR patients versus 3-20 days in OPEN patients. ${ }^{36-45}$ This difference could be explained by the fact that the cited studies included fairly small patient groups. Also, in contrast with other studies, we excluded all patients without symptomatic rAAA, which is likely to reduce the length of ICU and hospital stay.

\section{Mortality}

No significant difference in 30-day mortality rates were detected between eEVAR and OPEN, which is consistent with a recent randomized controlled trial by Reimerink et al which included 116 cases and described a 30-day mortality rate of $25 \%$ and $21 \%$, respectively. ${ }^{28}$ The IMPROVE trial (ClinicalTrials.gov identifier NCT01282996) reported similar results, describing no statistically significant difference in 30-day mortality rates between rAAA-treated patients who underwent eEVAR (35.4\%) and OPEN (37.4\%). Remarkably, we found no statistically significant difference in 30-day operation-related mortality after differentiating per age group. This could be because we excluded extremely frail patients from operative treatment. Addition of patients with rAAA to our analysis, who did not receive operative repair, defined as rAAA-related mortality, resulted in significantly higher mortality among octogenarians than in younger patients. With appropriate selection, we consider that octogenarians in good condition could have the same outcome as younger patients undergoing emergency operative repair for rAAA. However, rAAA is more frequent in males. Further, in most Western societies, life expectancy is known to be shorter for males compared with females and a higher mortality is expected, so this should be borne in mind when interpreting these results.

Current studies on quality of life after EVAR in octogenarians report that recovery to the baseline level of functioning seems to last at least 1 year. ${ }^{46}$ However, quality of life is probably even more impaired after OPEN. Despite acceptable outcomes in selected elderly patients, results in terms of quality of life should be taken into account in clinical decision-making with regard to whether or not to intervene in a case of rAAA.

\section{Limitations}

Because of its retrospective nature, our study has some limitations that should be considered when interpreting its results. Patients considered unstable on arrival to hospital did not receive $\mathrm{CT}$ scanning and were taken directly to the operating theater for OPEN, and this contributes to a significant selection bias. Anatomic suitability was certainly a source of significant bias in this study, as it is certainly the main determining factor regarding whether to perform eEVAR or not. Indeed, anatomic suitability also significantly influenced the decision whether or not to operate, as mentioned earlier. The number of patients in the present study does not permit further analyses, particularly given that the numbers of octogenarian patients included were small. Another possible limitation of this study may be the restriction of data collection to only one hospital, which might not be completely representative for all hospitals.

\section{Conclusion}

The 30-day and 5-year mortality rates following survival of patients with rAAA are similar for eEVAR and OPEN, 
despite the increased cardiac morbidity after OPEN. No major increase in 30-day mortality with age could be observed in octogenarians undergoing surgical repair in this study. However, particularly frail and very elderly patients receive no rAAA repair. Selection as to whether to intervene in a case of rAAA should not be made on the basis of age alone, but also in relation to comorbidity and patient preference.

\section{Disclosure}

The authors report no conflicts of interest in this work.

\section{References}

1. Opfermann P, von Allmen R, Diehm N, Widmer MK, Schmidli J, Dick F. Repair of ruptured abdominal aortic aneurysm in octogenarians. Eur $J$ Vasc Endovasc Surg. 2011;42(4):475-483.

2. Hoornweg LL, Storm-Versloot MN, Ubbink DT, Koelemay MJ, Legemate DA, Balm R. Meta analysis on mortality of ruptured abdominal aortic aneurysms. Eur J Vasc Endovasc Surg. 2008;35(5): 558-570.

3. EVAR Trial Participants. Endovascular aneurysm repair and outcome in patients unfit for open repair of abdominal aortic aneurysm (EVAR trial 2): randomised controlled trial. Lancet. 2005;365(9478): 2187-2192.

4. Yusuf SW, Whitaker SC, Chuter TA, Wenham PW, Hopkinson BR Emergency endovascular repair of leaking aortic aneurysm. Lancet. 1994;344(8937):1645.

5. Prusa AM, Wolff KS, Sahal M, et al. Abdominal aortic aneurysms and concomitant diseases requiring surgical intervention: simultaneous operation versus staged treatment using endoluminal stent grafting. Arch Surg. 2005;140(7):686-691.

6. Biancari F, Venermo M; Finnish Arterial Disease Investigators. Open repair of ruptured abdominal aortic aneurysm in patients aged 80 years and older. Br J Surg. 2011;98(12):1713-1718.

7. Balm R. Endovascular repair of ruptured abdominal aortic aneurysm. Br J Surg. 2008;95(2):133-134.

8. Prinssen M, Verhoeven EL, Buth J, et al. A randomized trial comparing conventional and endovascular repair of abdominal aortic aneurysms. N Engl J Med. 2004;351(16):1607-1618.

9. Wibmer A, Schoder M, Wolff KS, et al. Improved survival after abdominal aortic aneurysm rupture by offering both open and endovascular repair. Arch Surg. 2008;143(6):544-549.

10. Dormandy JA, Rutherford RB. Management of peripheral arterial disease (PAD). TASC Working Group. TransAtlantic Inter-Society Consensus (TASC). J Vasc Surg. 2000;31(1 Pt 2):S1-S296.

11. Fleisher LA, Beckman JA, Brown KA, et al. ACC/AHA 2007 Guidelines on Perioperative Cardiovascular Evaluation and Care for Noncardiac Surgery: Executive Summary: A Report of the American College of Cardiology/American Heart Association Task Force on Practice Guidelines (Writing Committee to Revise the 2002 Guidelines on Perioperative Cardiovascular Evaluation for Noncardiac Surgery): Developed in Collaboration With the American Society of Echocardiography, American Society of Nuclear Cardiology, Heart Rhythm Society, Society of Cardiovascular Anesthesiologists, Society for Cardiovascular Angiography and Interventions, Society for Vascular Medicine and Biology, and Society for Vascular Surgery. Circulation. 2007;116(17):1971-1996.

12. Cook Medical. Choosing the right EVAR device for your patients. Available from: http://www.cookmedical.com/ai/datasheetFeature. do?id=2152. Accessed August 9, 2014.

13. Medtronic. Endurant II AAA stent graft system. Available from: http:// www.medtronic.com/for-healthcare-professionals/products-therapies/ cardiovascular/aortic-stent-grafts/endurantII/index.htm. Accessed August 9, 2014.
14. Chaikof EL, Brewster DC, Dalman RL, et al. The care of patients with an abdominal aortic aneurysm: the Society for Vascular Surgery practice guidelines. J Vasc Surg. 2009;50(4 Supp1):S2-S49.

15. Moll FL, Powell JT, Fraedrich G, et al. Management of abdominal aortic aneurysms clinical practice guidelines of the European society for vascular surgery. Eur J Vasc Endovasc Surg. 2011;41 Suppl 1:S1-S58.

16. Marang-van de Mheen PJ, Kievit J. [Automated registration of adverse events in surgical patients in the Netherlands: the current status]. Ned Tijdschr Geneeskd. 2003;147(26):1273-1277. Dutch.

17. Roukema JA, van der Werken C, Leenen LP. [Registration of postoperative complications to improve the results of surgery]. Ned Tijdschr Geneeskd. 1996;140(14):781-784. Dutch.

18. Marang-van de Mheen PJ, van Hanegem N, Kievit J. Effectiveness of routine reporting to identify minor and serious adverse outcomes in surgical patients. Qual Saf Health Care. 2005;14(5):378-382.

19. Marang-van de Mheen PJ, Stadlander MC, Kievit J. Adverse outcomes in surgical patients: implementation of a nationwide reporting system. Qual Saf Health Care. 2006;15(5):320-324.

20. Marang-van de Mheen PJ, van Duijn-Bakker N, Kievit J. Surgical adverse outcomes and patients' evaluation of quality of care: inherent risk or reduced quality of care? Qual Saf Health Care. 2007;16(6):428-433.

21. National Public Health Compass. [A Digital Guide by and for Professionals]. Available from: http://www.nationaalkompas.nl. Accessed August 9, 2014. Dutch.

22. Boyle JR, Gibbs PJ, Kruger A, Shearman CP, Raptis S, Phillips MJ. Existing delays following the presentation of ruptured abdominal aortic aneurysm allow sufficient time to assess patients for endovascular repair. Eur J Vasc Endovasc Surg. 2005;29(5):505-509.

23. Bradbury AW, Makhdoomi KR, Adam DJ, Murie JA, Jenkins AM, Ruckley CV. Twelve-year experience of the management of ruptured abdominal aortic aneurysm. Br J Surg. 1997;84(12):1705-1707.

24. Heikkinen M, Salenius JP, Auvinen O. Ruptured abdominal aortic aneurysm in a well-defined geographic area. J Vasc Surg. 2002;36(2): 291-296.

25. Giles KA, Hamdan AD, Pomposelli FB, Wyers MC, Dahlberg SE, Schermerhorn ML. Population-based outcomes following endovascular and open repair of ruptured abdominal aortic aneurysms. J Endovasc Ther. 2009;16(5):554-564.

26. Giles KA, Pomposelli FB, Hamdan AD, Wyers MC, Schermerhorn ML. Comparison of open and endovascular repair of ruptured abdominal aortic aneurysms from the ACS-NSQIP 2005-2007. J Endovasc Ther. 2009;16(3):365-372.

27. Greco G, Egorova N, Anderson PL, et al. Outcomes of endovascular treatment of ruptured abdominal aortic aneurysms. J Vasc Surg. 2006; 43(3):453-459.

28. Reimerink JJ, Hoornweg LL, Vahl AC, et al. Endovascular repair versus open repair of ruptured abdominal aortic aneurysms: a multicenter randomized controlled trial. Ann Surg. 2013;258(2):248-256.

29. Antoniou GA, Georgiadis GS, Antoniou SA, et al. Endovascular repair for ruptured abdominal aortic aneurysm confers an early survival benefit over open repair. J Vasc Surg. 2013;58(4):1091-1105.

30. Giles KA, Landon BE, Cotterill P, O’Malley AJ, Pomposelli FB, Schermerhorn ML. Thirty-day mortality and late survival with reinterventions and readmissions after open and endovascular aortic aneurysm repair in Medicare beneficiaries. J Vasc Surg. 2011;53(1): 6-12, 13.e11.

31. Edwards ST, Schermerhorn ML, O’Malley AJ, et al. Comparative effectiveness of endovascular versus open repair of ruptured abdominal aortic aneurysm in the Medicare population. J Vasc Surg. 2014;59(3): 575-582.e576.

32. Peppelenbosch N, Geelkerken RH, Soong C, et al. Endograft treatment of ruptured abdominal aortic aneurysms using the Talent aortouniiliac system: an international multicenter study. J Vasc Surg. 2006;43(6):1111-1123.

33. Anain PM, Anain JM Sr, Tiso M, Nader ND, Dosluoglu HH. Early and mid-term results of ruptured abdominal aortic aneurysms in the endovascular era in a community hospital. J Vasc Surg. 2007;46(5):898-905. 
34. Lee RW, Rhodes JM, Singh MJ, et al. Is there a selection bias in applying endovascular aneurysm repair for rupture? Ann Vasc Surg. 2008; 22(2):215-220.

35. Vogel TR, Dombroversuskiy VY, Haser PB, Graham AM. Has the implementation of EVAR for ruptured AAA improved outcomes? Vasc Endovascular Surg. 2009;43(3):252-257.

36. Brandt M, Walluscheck KP, Jahnke T, Graw K, Cremer J, MullerHulsbeck S. Endovascular repair of ruptured abdominal aortic aneurysm: feasibility and impact on early outcome. J Vasc Interv Radiol. 2005;16(10):1309-1312.

37. Franks S, Lloyd G, Fishwick G, Bown M, Sayers R. Endovascular treatment of ruptured and symptomatic abdominal aortic aneurysms. Eur J Vasc Endovasc Surg. 2006;31(4):345-350.

38. Kapma MR, Verhoeven EL, Tielliu IF, et al. Endovascular treatment of acute abdominal aortic aneurysm with a bifurcated stentgraft. Eur J Vasc Endovasc Surg. 2005;29(5):510-515.

39. Peppelenbosch N, Yilmaz N, van Marrewijk C, et al. Emergency treatment of acute symptomatic or ruptured abdominal aortic aneurysm. Outcome of a prospective intent-to-treat by EVAR protocol. Eur J Vasc Endovasc Surg. 2003;26(3):303-310.

40. Alsac JM, Desgranges P, Kobeiter H, Becquemin JP. Emergency endovascular repair for ruptured abdominal aortic aneurysms: feasibility and comparison of early results with conventional open repair. Eur J Vasc Endovasc Surg. 2005;30(6):632-639.
41. Reichart M, Geelkerken RH, Huisman AB, van Det RJ, de Smit P, Volker EP. Ruptured abdominal aortic aneurysm: endovascular repair is feasible in $40 \%$ of patients. Eur J Vasc Endovasc Surg. 2003; 26(5):479-486.

42. Resch T, Malina M, Lindblad B, Dias NV, Sonesson B, Ivancev K. Endovascular repair of ruptured abdominal aortic aneurysms: logistics and short-term results. J Endovasc Ther. 2003;10(3):440-446.

43. Vaddineni SK, Russo GC, Patterson MA, Taylor SM, Jordan WD Jr. Ruptured abdominal aortic aneurysm: a retrospective assessment of open versus endovascular repair. Ann Vasc Surg. 2005;19(6):782-786.

44. van Sambeek MR, van Dijk LC, Hendriks JM, et al. Endovascular versus conventional open repair of acute abdominal aortic aneurysm: feasibility and preliminary results. J Endovasc Ther. 2002;9(4):443-448.

45. Yilmaz N, Peppelenbosch N, Cuypers PW, Tielbeek AV, Duijm LE, Buth J. Emergency treatment of symptomatic or ruptured abdominal aortic aneurysms: the role of endovascular repair. J Endovasc Ther. 2002;9(4):449-457.

46. Pol RA, Zeebregts CJ, van Sterkenburg SM, et al. Outcome and quality of life after endovascular abdominal aortic aneurysm repair in octogenarians. J Vasc Surg. 2014;60(2):308-317.
Clinical Interventions in Aging

\section{Publish your work in this journal}

Clinical Interventions in Aging is an international, peer-reviewed journal focusing on evidence-based reports on the value or lack thereof of treatments intended to prevent or delay the onset of maladaptive correlates of aging in human beings. This journal is indexed on PubMed Central, MedLine,

\section{Dovepress}

CAS, Scopus and the Elsevier Bibliographic databases. The manuscript management system is completely online and includes a very quick and fair peer-review system, which is all easy to use. Visit http://www.dovepress. com/testimonials.php to read real quotes from published authors. 